\title{
The Use of Bulk Fill Resin-Based Composite in the Sealing of Cavity with Margins in Radicular Cementum
}

\author{
Puleio Francesco ${ }^{1}$ Cervino Gabriele ${ }^{1, \odot}$ Luca Fiorillo ${ }^{1,2}$ Miragliotta Giuseppe ${ }^{1}$ Squillacioti \\ Antonella ${ }^{1}$ Bruno Giancarlo ${ }^{1}$ Pinizzotto Mirta ${ }^{1}$ João Paulo Mendes Tribst ${ }^{3} \quad$ Roberto Lo Giudice ${ }^{4}$ \\ ${ }^{1}$ Department of Biomedical and Dental Sciences and \\ Morphofunctional Imaging, Messina University, Messina, Italy \\ ${ }^{2}$ Multidisciplinary Department of Medical-Surgical and \\ Odontostomatological Specialties, University of Campania "Luigi \\ Vanvitelli," Naples, Italy \\ ${ }^{3}$ Department of Dental Materials and Prosthodontics, Institute of \\ Science and Technology, São Paulo State University, São José dos \\ Campos, Brazil \\ ${ }^{4}$ Department of Clinical and Experimental Medicine, Messina \\ University, Messina, Italy \\ Eur J Dent 2022;16:1-13. \\ Address for correspondence Luca Fiorillo, DDS, MSc, \\ PhD, Department of Biomedical and Dental Sciences and \\ Morphofunctional Imaging, Messina University, Messina 98100, Italy \\ (e-mail: Ifiorillo@unime.it).
}

\section{Abstract \\ Keywords \\ - bulk fill resin \\ - composite \\ - conservative dentistry \\ - radicular cementum \\ - sealing}

The aim of this systematic review was to evaluate if the newly introduced bulk fill resin-based composite provides a better marginal sealing in cavity preparations with margins in dental cementum. The population investigation comparison outcome (PICO) framework was: in cavity preparation with margins in dental cementum of human extracted teeth, do bulk fill resin base composites provide a better marginal sealing than non-bulk fill resin-based composites? We performed our research on April 21, 2020. Two authors independently evaluated the abstract and titles for eligibility criteria. Two authors independently extracted the data and assessed the risk of bias in single studies. After the initial screening of 400 abstract and titles, the full text of the articles, that could meet the eligibility criteria, were obtained via the university library. A total of 36 full-text articles were evaluated; 11 articles were finally eligible for the review. Eight studies showed statistically differences, but not significant, in the marginal sealing between bulk fill and nonbulk fill resin-based composite $(p>0.05)$. One study showed statistically significant differences: SonicFill and Grandio showed better marginal sealing than GrandioSo and SDR(r) (Sirona Dentsply, New York, United States) and the latter two showed better marginal sealing than Filtek Supreme $(p<$ $0.05)$. One study showed statistically significant less marginal gap of SDR than Filtek Bulk Fill $(p=0.0015)$ and Filtek Supreme $(p<0.0001)$. One study showed SDR to have a significantly higher microleakage than the other materials tested $(p<0.05)$. Based on our current literature review, there are not enough data to establish if bulk fill resin base composite provides a better or a worse marginal sealing at cementum margins. published online

September 10, 2021
DOI https://doi.org/ $10.1055 / \mathrm{s}-0041-1731834$ ISSN 1305-7456
(C) 2021. The Author(s).

This is an open access article published by Thieme under the terms of the Creative Commons Attribution License, permitting unrestricted use, distribution, and reproduction so long as the original work is properly cited. (https:// creativecommons. org/licenses/by/4.0/).

Thieme Medical and Scientific Publishers Pvt. Ltd. A-12, 2nd Floor, Sector 2, Noida-201301 UP, India 


\section{Introduction}

\section{Rationale}

With the increase in the average age and with the general improvement in the oral health conditions of the population, there is more and more often a greater presence of dental elements in the oral cavity of older patients than in previous times. ${ }^{1}$ The prevalence of root surface exposures correlates positively with the age of the patient: consequently, the prevalence of carious involvement of the root surface increases. ${ }^{2}$ Root cementum is a surface with a reactivity ${ }^{3}$ greater than that of enamel and this makes it more susceptible to the action of endogenous metalloproteases as well as bacterial ones. ${ }^{4}$

Microleakage is defined as the passage of bacteria and their toxins through the margins of the restoration and the tooth surface of the cavity preparation. ${ }^{5}$ The anatomical basis of this phenomenon is the marginal gap between the restoration and the dental tissues; the clinical implications could be postoperative sensitivity, dentinal sensitivity, and development of secondary caries. ${ }^{6}$ Hydrolytic degradation of the adhesive bond, which can occur both on the adhesive component and on the collagen of the dental tissue, happens more frequently when the margins of the restoration are not placed in enamel. $^{7}$

As highlighted by Lo Giudice et al, $^{8}$ a restoration that has a cement margin represents challenge for adhesive dentistry techniques: in fact, the higher percentage of organic material $(23 \%)$ of the root cementum, compared with enamel (1-2\%), makes cementum a substrate that exhibits weaker and less predictable adhesion parameters. Furthermore, it must be emphasized that the presence of failure and marginal fractures is not eliminated by the use of new adhesives with higher adhesion values. ${ }^{9,10}$ Adhesion to cement/dentin is in fact the weak point of the adhesive restoration due to several factors: hydrolysis of the adhesive layer, inadequate infiltration of the adhesive into the substrate, and incomplete evaporation of the solvent. Some of these drawbacks can be modified by varying the type of adhesive strategy ${ }^{11}$ : for example, the use of functional monomers inside the adhesive makes possible to obtain an adhesive layer through the phenomenon of "nano layering"12 preventing hydrolytic degradation of the adhesive layer. ${ }^{13}$ Evidence also suggests that a total etch approach produces less marginal discoloration in vivo, without improving postoperative sensitivity, ${ }^{14}$ but in conclusion neither a total etch approach nor a self-etch approach can guarantee the development of a hybrid layer without porosity. ${ }^{15}$

The marginal gap is directly correlated to the shrinkage stress of the material and its elastic modulus. The elastic modulus is a characteristic of the material, while the shrinkage stress is related both to the material and to other factors (for example the cavity configuration). ${ }^{16}$ The gold standard materials for restorative dentistry are resin-based composites due to their characteristics. ${ }^{17}$ These materials also find application in the cervical region of the dental element where they show better in vivo performances than glass ionomer cements. ${ }^{18}$

One of the major drawbacks of traditional composite materials is their polymerization shrinkage, which can also be considerable and can reach 3 to $7 \%$ of the initial mass, ${ }^{19-22}$ contributing to the formation of marginal gap.

Traditional composites must be deposited using the incremental technique both to reduce the effects of polymerization shrinkage and to promote complete polymerization of the material. ${ }^{23-26}$ It has also been shown that the use of the composite with the bulk technique produces a high cusp deflection. ${ }^{27,28}$

The need for a material with low polymerization shrinkage has led to the development of a several resin-based composite materials (siloranes, ormocers, nano-filled composites) that exhibit lower polymerization shrinkage than conventional composites. However, they still need to be deposited in maximum increments of $\sim 2 \mathrm{~mm}$ due to their limited depth of polymerization ${ }^{29}$ and some are also impractical due to the need for a specific adhesive system..$^{30,31}$ A further improvement in the technology has led to the development of materials that have both a reduced polymerization shrinkage and an increased depth of cure (DOC). The combination of these two characteristics allows the material to be deposited in increments greater than $2 \mathrm{~mm}$ of the nonbulk composite.

The optimization of the DOC is achieved through different strategies:

- An increase in translucency ${ }^{32,33}$ typical of all bulk composites, with the exception of SonicFill (Kerr);

- A modulation of the photo-polymerization that is obtained, in addition to the presence of camphorquinone and tertiary amines, by specific modulators. Tetric EvoCeram Bulk Fill (Ivoclar Vivadent) contains an additional photo-initiator: Ivocerin (derivative of dibenzoyl germanium $).^{34}$

- By new functional monomers: many bulk composites contain modified Uretandimetacrylate (UDMA) with photo-active groups that would act as modulators of photo-polymerization. ${ }^{35}$

In 2010, the first resin-based composite was developed that could be deposited in increments of up to $4 \mathrm{~mm} .{ }^{36}$ This new class of materials is collectively referred to as "bulk fill resin-based composites." These composites are heterogeneous in composition and commercial presentation therefore a satisfactory classification is difficult, if not impossible. However, classifying bulk composites according to viscosity, we can divide bulk composites into three classes (see - Tables 1 and 2 ).

- Bulk-fill resin based composite (RBC) with low viscosity or "base," used as the base of the restoration that must be covered by a layer of no-bulk composite (according to the manufacturer's instructions).

- Bulk-fill high viscosity or "full body" that can be used throughout the restoration, but may sometimes require a nonbulk composite cap (according to the manufacturer's instructions). 


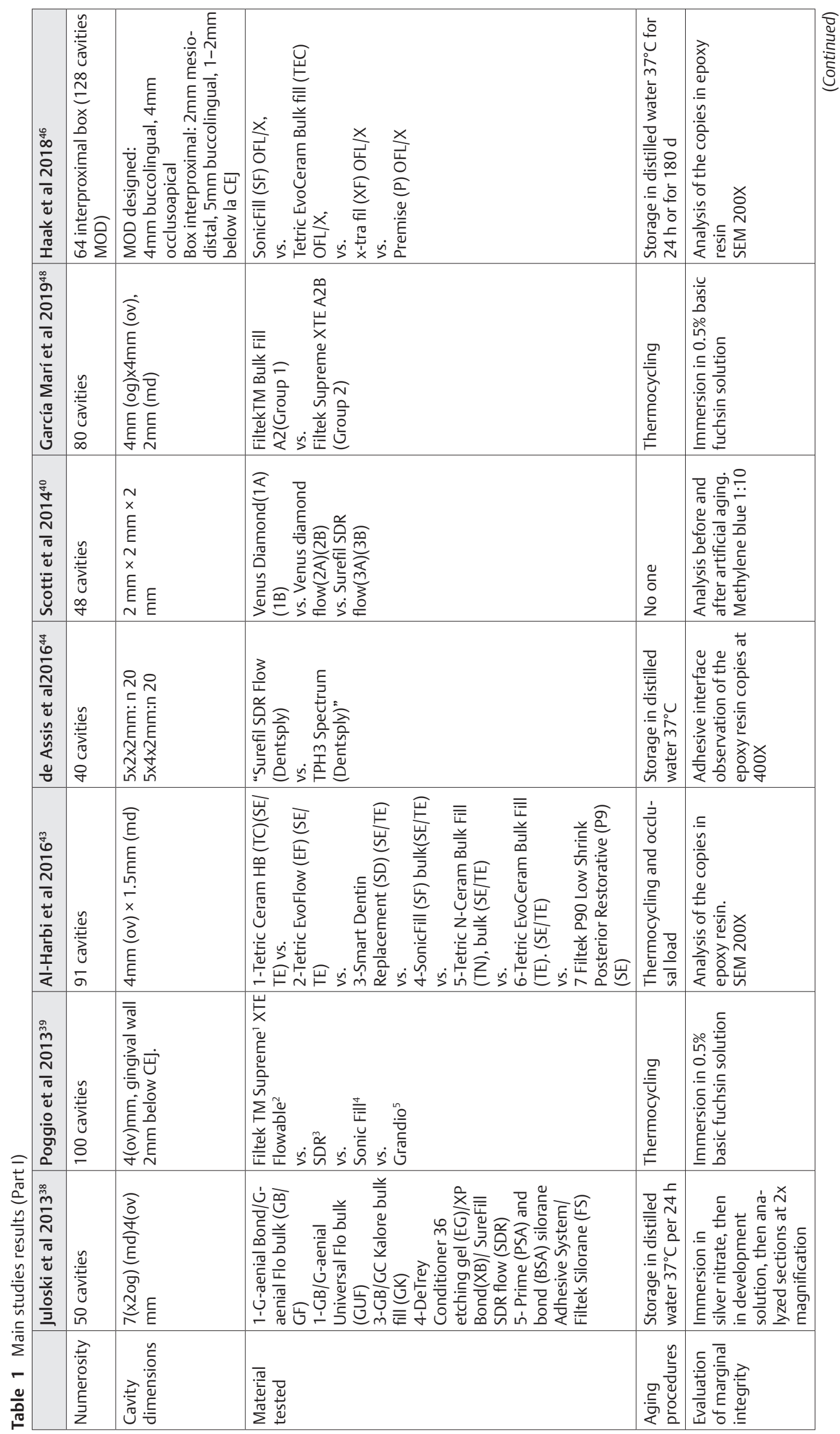




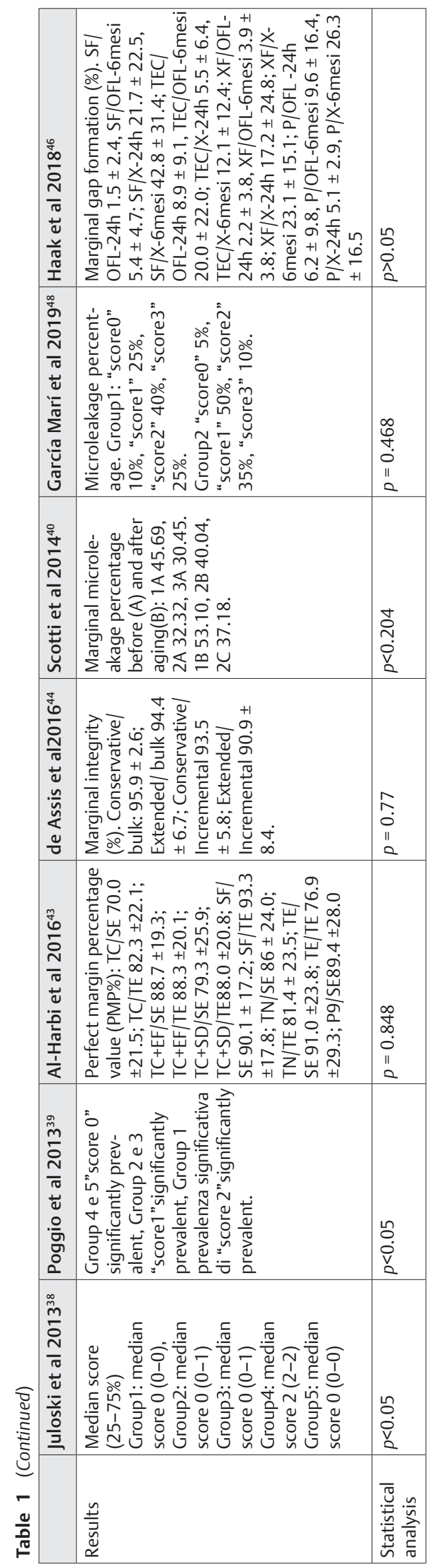

European Journal of Dentistry Vol. 16 No. 1/2022 (c) 2021. The Author(s). 
Bulk Resins in the Sealing with Margin in Reticular Cementum Francesco et al. 5

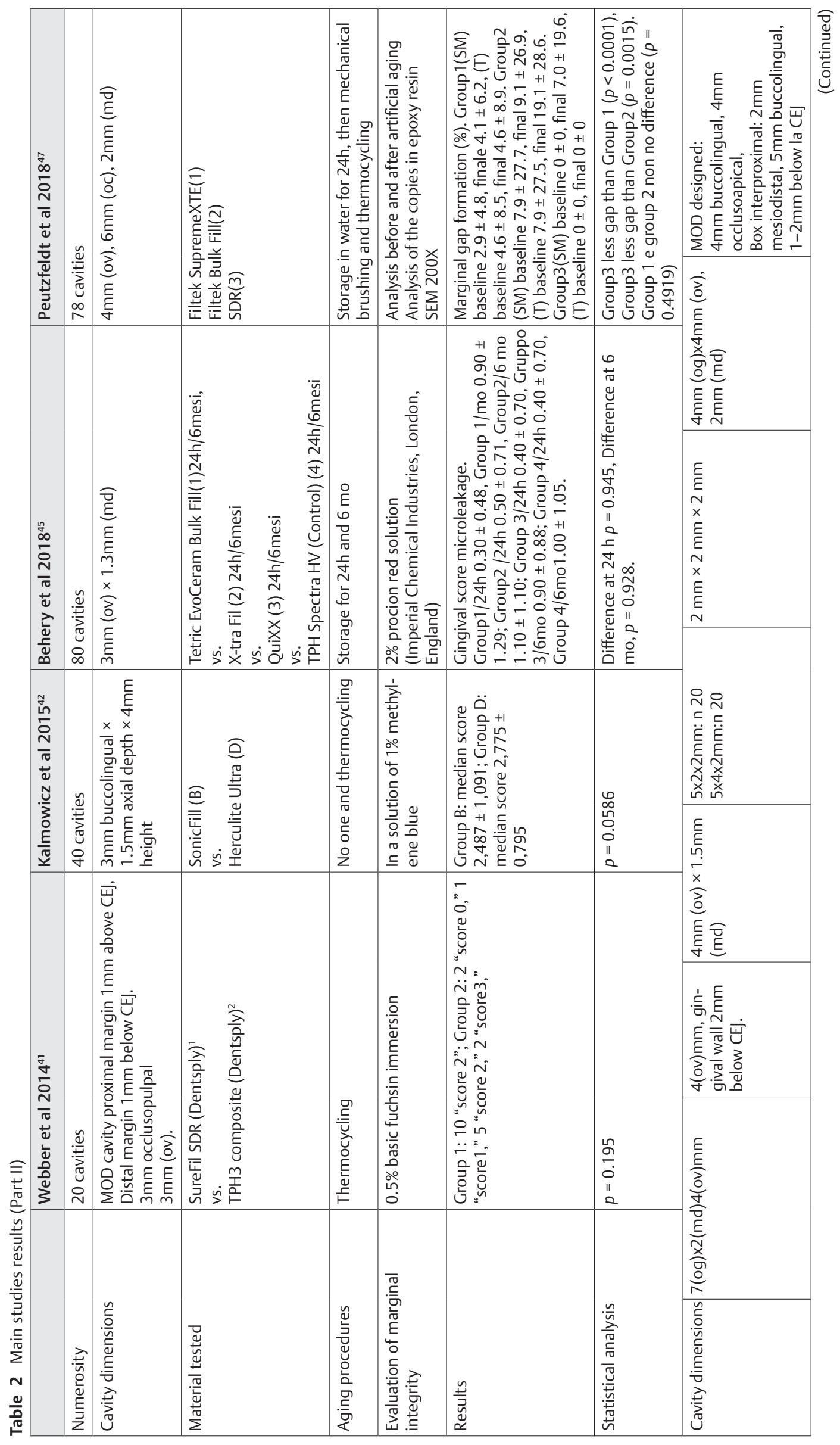




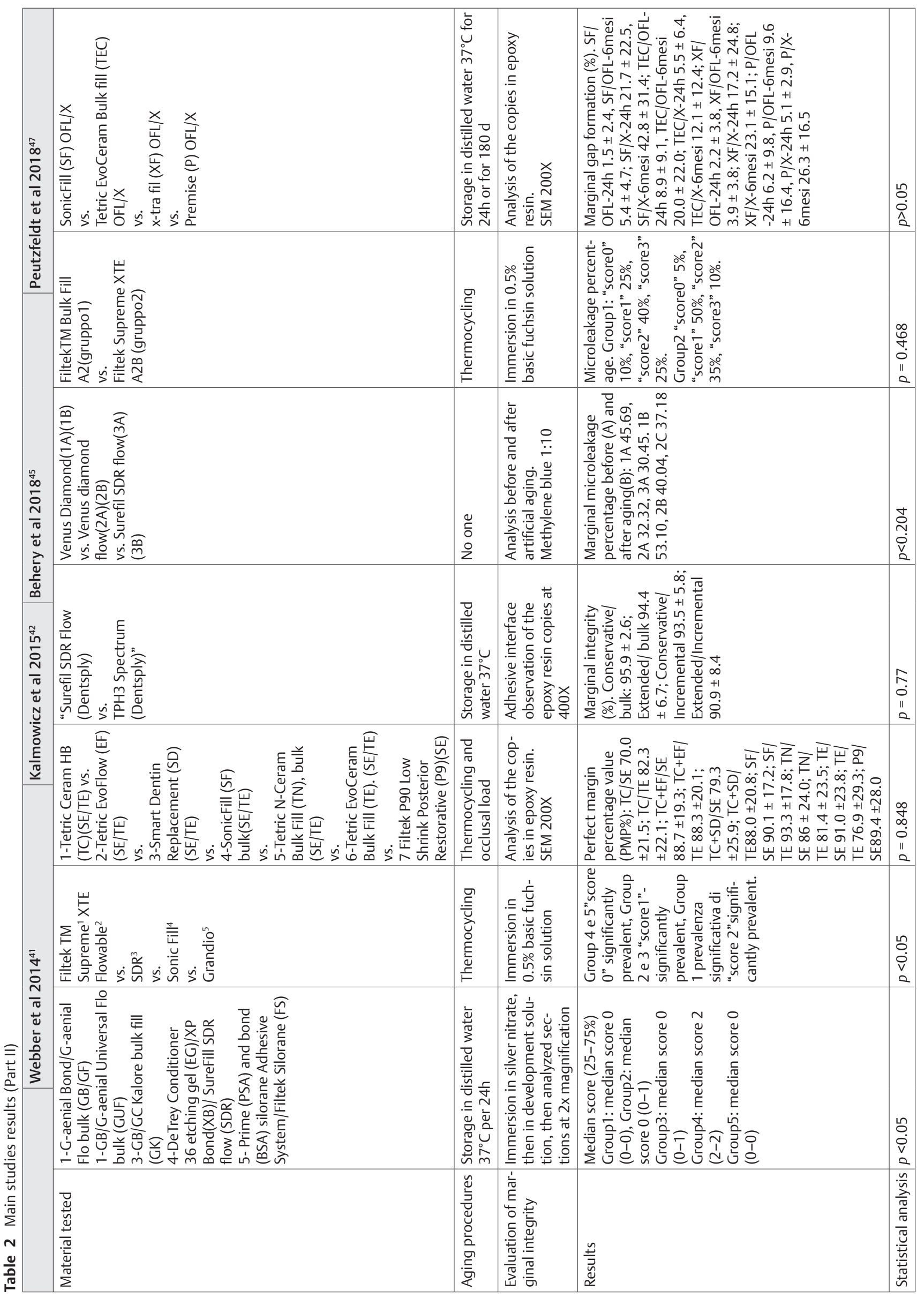


Table 3 Risk of bias (Part I)

\begin{tabular}{|c|c|c|c|c|c|c|c|c|}
\hline Item & $\begin{array}{l}\text { Poggio } \\
\text { et al } \\
2013^{39}\end{array}$ & $\begin{array}{l}\text { Juloski } \\
\text { et al } \\
2013^{38}\end{array}$ & $\begin{array}{l}\text { Scotti et } \\
\text { al } 2014^{40}\end{array}$ & $\begin{array}{l}\text { Webber et } \\
\text { al } 2014^{41}\end{array}$ & $\begin{array}{l}\text { Kalmowicz } \\
\text { et al } 2015^{42}\end{array}$ & $\begin{array}{l}\text { Al-Harbi et } \\
\text { Al } 2016^{43}\end{array}$ & $\begin{array}{l}\text { de Assis } \\
\text { et al } \\
2016^{44}\end{array}$ & $\begin{array}{l}\text { Haak et a } \\
2018^{46}\end{array}$ \\
\hline $\begin{array}{l}\text { Adequate sequence } \\
\text { generation }\end{array}$ & Unclear & Unclear & No & No & Unclear & No & No & Unclear \\
\hline Allocation concealment & No & No & No & No & No & No & No & No \\
\hline $\begin{array}{l}\text { Blinding of participants } \\
\text { and personnel }\end{array}$ & No & No & No & No & No & No & No & No \\
\hline $\begin{array}{l}\text { Blinding of outcome } \\
\text { assessment }\end{array}$ & Yes & No & No & Yes & Yes & No & Yes & Yes \\
\hline $\begin{array}{l}\text { Incomplete outcome } \\
\text { data addressed }\end{array}$ & No & No & No & No & No & No & No & No \\
\hline $\begin{array}{l}\text { Free of selective } \\
\text { reporting }\end{array}$ & Yes & Yes & Yes & Yes & Yes & Yes & Yes & Yes \\
\hline Free of other bias & Yes & Yes & No & Yes & No & Yes & Yes & Yes \\
\hline
\end{tabular}

\section{Bulk-Fill RBC That Require Sonic Activation}

The practical consequences are considerable. The positioning of a restoration with a cement margin represents a challenge for the clinician associated with the problem of time: the cervical area, in fact, is difficult to control and to access; moreover, it is difficult to maintain adequate isolation for a relatively long period. Moreover, it is shown that the contamination of the cavity preparation with a hemostatic agent significantly reduces the marginal seal on cement, interfering with the adhesive procedures. ${ }^{37}$

Therefore, the possibility of using a material that has optimized physical characteristics and also allows shorter processing times is fascinating.

\section{Objectives}

Our aim is to answer the following question according to the PICOS scheme: in cavity preparation with margins in dental cementum of human extracted teeth, do bulk fill resin base composites provide a better marginal sealing than non-bulk fill resin-based composites?

\section{Methods}

\section{Eligibility Criteria}

The search strategy, performed using the PubMed controlled vocabulary and free terms, was defined on the basis of the following elements of the PICO question:

Population (P): Cavity preparations with at least one margin in root cementum of human teeth.

Intervention (I): restoration made with a bulk fill composite.

Comparison (C): restoration made with a nonbulk composite (resin-based composite).

Outcome (0): marginal integrity and/or microleakage

Study design (S): in vitro studies.

The eligibility criteria are: in vitro studies, published in the last 10 years (given the date of introduction of the material on the market) and written in English, it was decided to include studies on human teeth and in vitro studies to have a standardization of the cavity, which would not be possible to obtain in an in vivo study.

Were included studies that explicitly described that a cavity margin of the preparation was in the root cement. Finally, comparative studies between a bulk fill composite and a nonbulk composite were chosen.

\section{Information Sources}

To identify the literature of our interest, a search was performed on PubMed, Scopus, Google Scholar, Semantic Scholar, and on gray literature via OpenGrey.eu.

\section{Search}

In the construction of this research, we wanted to combine three fundamental concepts: the anatomical site, the concept of microinfiltration, and the material (-Fig. 1).

On April 21, 2020, the following searches were performed:

\section{Search on PUBMED}

\# 1. "dental cementum" OR "root caries" OR "tooth root" OR dentin

\# 2. "dental leakage" OR "dental marginal adaptation"

\# 3. "filtek bulk fill” OR "SDR composite" OR "composite resins" OR "dental bonding" OR "dentin-bonding agents" OR "dental cement" OR "resin cements"

("Tooth Root" [Mesh] OR "Dentin" [Mesh] OR “Dental Cementum" [Mesh]) AND ("Dental Leakage" [Mesh] OR "Dental Marginal Adaptation" [Mesh]) AND ("Filtek Bulk Fill” [Supplementary Concept] OR "Composite Resins" [Mesh] OR "SDR composite" [Supplementary Concept] OR "Dental Bonding” [Mesh] OR "Dentin-Bonding Agents" [Mesh] OR “Dental Cements” [Mesh] OR “Resin Cements “[Mesh])

\section{Search on Scopus}

\# 1 Cementum OR “root surface” OR “dental cementum” OR "tooth root" OR "cement enamel junction" OR "tooth cementum" OR "tooth cervix" OR "dental cementum” OR “dental cementum” OR "root caries" 
Table 4 Risk of bias (Part II)

\begin{tabular}{|l|l|l|l|}
\hline & Behery et al $2018^{45}$ & Peutzfeldt et al 2018 & García Marí et al 2019.8 \\
\hline Adequate sequence generation? & No & No & No \\
\hline Allocation concealment? & No & No & No \\
\hline Blinding of participants and personnel? & No & No & No \\
\hline Blinding of outcome assessment? & No & No & Yes \\
\hline Incomplete outcome data addressed? & No & No & No \\
\hline Free of selective reporting? & Yes & Yes & Yes \\
\hline Free of other bias? & Yes & Yes & Yes \\
\hline
\end{tabular}

Table 5 Risk of bias (Part III)

\begin{tabular}{|c|c|c|c|c|c|c|c|c|c|c|c|}
\hline Item & $\begin{array}{l}\text { Poggio } \\
\text { et al } \\
2013^{39}\end{array}$ & $\begin{array}{l}\text { Juloski } \\
\text { et al } \\
2013^{38}\end{array}$ & $\begin{array}{l}\text { Scotti } \\
\text { et al } \\
2014^{40}\end{array}$ & $\begin{array}{l}\text { Webber } \\
\text { et al } \\
2014^{41}\end{array}$ & $\begin{array}{l}\text { Kalmowicz } \\
\text { et al } \\
2015^{42}\end{array}$ & $\begin{array}{l}\text { Al-Harbi } \\
\text { et al } \\
2016^{43}\end{array}$ & $\begin{array}{l}\text { de Assis } \\
\text { et al } \\
2016^{44}\end{array}$ & $\begin{array}{l}\text { Haak } \\
\text { et al } \\
2018^{46}\end{array}$ & $\begin{array}{l}\text { Behery et } \\
\text { al } 2018^{45}\end{array}$ & $\begin{array}{l}\text { Peutzfeldt et } \\
\text { al } 2018^{47}\end{array}$ & $\begin{array}{l}\text { García Marí et } \\
\text { al } 2019^{48}\end{array}$ \\
\hline $\begin{array}{l}\text { Random } \\
\text { sequence } \\
\text { generation }\end{array}$ & & & & & & & & & & & \\
\hline $\begin{array}{l}\text { Allocation } \\
\text { concealme }\end{array}$ & & & & & & & & & & & \\
\hline $\begin{array}{l}\text { Blinding of } \\
\text { participant } \\
\text { personnel }\end{array}$ & & & & & & & & & & & \\
\hline $\begin{array}{l}\text { Blinding of } \\
\text { outcome } \\
\text { assessmen }\end{array}$ & & & & & & & & & & & \\
\hline $\begin{array}{l}\text { Incomplete } \\
\text { outcome d }\end{array}$ & & & & & & & & & & & \\
\hline $\begin{array}{l}\text { Selective } \\
\text { reporting }\end{array}$ & & & & & & & & & & & \\
\hline Other bias & & & & & & & & & & & \\
\hline
\end{tabular}

\# 2 Microleakage OR "dental leakage" OR "cervical microleakage" OR "dental restoration failure" OR "mineral interfaces" OR "marginal quality" OR "gap formation" OR "thooth hypersensitivity"

\# 3 "Composite resins" OR "dental composites" OR "resin-based composite" OR "bulk fill" OR "resin composite" OR "bulk-fill" OR "composite resin" OR "filtek bulk fill" OR "composite resin" OR "SDR composite" OR "dental bonding" OR "dentin bonding agents" OR "dental cement" OR "resin cement"

Additional searches were performed on Google scholar and semantic Scholar using the terms "bulk fill" and "microleakage"

A further search, which did not exclusively include PubMed indexed literature, was performed by combining the term "bulk fill," using the AND operator, from time to time to the terms II class, III class and V class to try to introduce the studies that referred to the design of the cavity rather than the concept of "root cement"
The results were limited to the last 10 years and to studies performed on the human species.

\section{Study Selection}

Two reviewers independently assessed the titles and abstracts of all of the studies. Any disagreement regarding the eligibility of the included studies was resolved through discussion and consensus or by a third reviewer.

\section{Data Collection Process}

The data collection strategy was defined on the basis of the characteristics of the PICOS model, to these characteristics were added explicitly through a predefined table. Data was collected based on the default table by the two reviewers.

\section{Data Items}

The $\boldsymbol{- T a b l e s} \mathbf{1}$ and $\mathbf{2}$ evaluate the general data (year, title, and author), the size of the sample (the number of cavities), the dimensions of the cavity, the materials tested, whether an artificial aging procedure has been performed, and the 
method used to evaluate the marginal integrity (immersion in dye and which dye or Scanning electron microscope evaluation of the epoxy replicas) and the results.

Within each publication, the data and statistical significance characteristics of the only interfaces between the restoration and the margin of the cavity preparation in root cement were collected.

\section{Risk of Bias in Individual Studies}

To define the validity of the individual studies, the risk of bias was determined using the "Cochrane Collaboration's tool for assessing risk of bias in randomized trials" (-Tables 3-5).

\section{Synthesis of Results}

A narrative summary of the studies included in the review was made. It was not possible to carry out a meta-analysis due to the heterogeneity of the studies.

\section{Results}

\section{Study Characteristics}

The 11 selected studies were deemed eligible based on the predetermined PICOS criteria. Methods: selected studies are in vitro studies, in English language

Participants: The studies evaluate experimental cavity preparations in human teeth, which expressly present at least one root cement margin, have a total of 691 (-Fig. 1).

Intervention: The intervention was the restoration with a bulk fill composite and the outcome evaluated was the degree of marginal adaptation.

Outcome: Data relating microinfiltration or marginal integrity were evaluated using different systems.

The summary data can be found in $\boldsymbol{- T a b l e s} \mathbf{1}$ and $\mathbf{2}$.

\section{Risk of Bias}

The risk of bias was performed using the "Cochrane Collaboration's tool for assessing risk of bias in randomized trials" ( - Tables 3-5).

\section{Results of Individual Studies}

In the study of Juloski et al, ${ }^{38} 50$ cavities were prepared, then the following materials were tested SureFil SDR flow versus Filtek Silorane versus G-ænial Flo bulk fill versus G-ænial Universal Flo bulk fill versus Kalore bulk fill, and the samples were stored for 24 hours at $37^{\circ} \mathrm{C}$ in distilled water, then immersed in silver nitrate, then in developer solution, and then sections were analyzed at $2 x$ magnification.

The results show that SDR has greater microleakage than other materials.

In the study of Poggio et al, ${ }^{39} 100$ cavities were prepared and then were restored with four different materials: Filtek TM Supreme XTE Flowable(1), SDR(2), Sonic Fill(3), and Grandio(4). The samples were subjected to thermocycling and then immersed in a $0.5 \%$ basic fuchsin solution. The results show that there is a difference according to the different composite used:

Sonic Fill and Grandio perform better than the, GrandioSo and SDR. Worst performance is seen with Filtek supreme.
In the study of Scotti et $\mathrm{al}_{1}{ }^{40} 48$ cavities restored with three different materials: Venus Diamond (1A) (1B), Venus diamond flow (2A) (2B), and Surefil SDR flow (3A) (3B). The samples were evaluated before (A) and after artificial aging (B) by thermocycling. The results show that the influence of the material is not statistically significant on the microleakage.

In the study by Webber et al, ${ }^{41} 20$ cavities were prepared, restored with SureFil SDR (Dentsply) ${ }^{1}$ and TPH3 composite (Dentsply). ${ }^{2}$ The samples were subjected to thermal cycling and immersed in basic fuchsin. The results show that there is no statistically significant difference in microinfiltration.

In the study Kalmowicz et al, ${ }^{42} 40$ cavities SonicFill (B), Herculite Ultra (D) were considered. An analysis was performed before and after thermocycling by immersion in methylene blue and observation. There were no statistically significant differences in microinfiltration.

In the study of Al-Harbi et $\mathrm{al}_{,}{ }^{43} 91$ cavities assigned to 13 restorative approaches were considered: in particular, the different materials were combined with a self-etch or total etch adhesive technique, with the exception of Filtek P90 applied only with self-etch technique: Tetric Ceram HB (TC) (SE / TE), TetricEvoFlow (EF) (SE / TE), Smart Dentin Replacement (SD) (SE / TE), SonicFill (SF) bulk (SE / TE), Tetric N-Ceram Bulk Fill (TN), bulk (SE / TE), Tetric EvoCeram Bulk Fill (TE) (SE / TE), Filtek P90 Low Shrink Posterior Restorative (P9) (SE). The specimens were subjected to thermal and occlusal cycling. SEM analysis of the copies in epoxy resin was performed. There is no statistically significant difference in marginal integrity.

In the study of de Assis et al, ${ }^{44} 40$ cavities were considered, assigned to two different restorative protocols: Surefil SDR Flow (Dentsply) and TPH3 Spectrum (Dentsply). Samples were stored in distilled water at $37^{\circ} \mathrm{C}$, and copies in SEM epoxy resin were observed. There is no statistically significant difference in marginal integrity between the materials tested.

In the study of Behery et $\mathrm{al}^{45} 80$ cavities were prepared for restoration with four different materials: Tetric EvoCeram Bulk Fill(1) 24 hours/6 months, X-traFil(2) 24 hours/6 months, QuiXX(3) 24 hours/6 months, and TPH Spectra HV (control) (4) 24 hours/6 months. The samples were stored at standard conditions for 24 hours or 6 months. Then dipped in Procyon red solution. The results show that there is no statistically significant difference between the gingival microleakage of the four groups after 24-hour storage and after 6-month storage.

In the study of Haak et $\mathrm{al}^{46} 64$ interproximal boxes were considered, restored with four different materials. The materials were used with two different adhesives each: SonicFill (SF) OFL/X, TetricEvoCeram Bulk fill (TEC) OFL/X, X-tra fil (XF) $\mathrm{OFL} / \mathrm{X}$, Permise (P) OFL/X. Following storage in distilled water at $37^{\circ} \mathrm{C}$ for 24 hours or 180 days, an analysis of the copies in epoxy resin was performed with SEM. The results highlight that there is no statistically significant difference between bulk fill composites and control.

In the study of Peutzfeldt et al, ${ }^{47} 78$ cavities restored with three different materials: Filtek SupremeXTE(1), Filtek 
Bulk Fill(2), and SDR(3) were made. The samples were treated by storage in water for 24 hours, then aging with mechanical brushing (SM) and thermocycling (T). Analysis of the SEM epoxy resin copies before and after artificial aging showed that the SDR material has the smallest marginal gap. There is no difference between Filtek Supreme and Filtek Bulk Fill.

In the study by García Marí et al, ${ }^{48} 80$ cavities were analyzed. Restored with two different materials: FiltekTM Bulk Fill A2 (group1) and Filtek Supreme XTE A2B (group2). The samples were subjected to thermocycling, then immersed in a $0.5 \%$ basic fuchsin solution. The analysis showed that the percentages of the microleakage score show nonstatistically significant differences between the various groups.

\section{Discussion}

A narrative summary of the studies included in the review was made. It was not possible to carry out a meta-analysis due to the heterogeneity of the methods and the evaluation of the results of the individual studies.

Despite the lack of a standardized protocol for the evaluation of bulk fill composites at the root cement interface, the studies analyzed do not reveal statistically significant differences in terms of marginal adaptation between the class of nonbulk fill composites and the class of bulk fill composites in eight of the studies analyzed ${ }^{40-46,48}$ (463 cavities).

However, three studies show statistically significant differences between tested materials:

Poggio et $\mathrm{al}^{39}$ showed that there is a statistically significant difference in terms of microinfiltration following immersion in basic fuchsin dye: in particular in their study the products SonicFill (bulk) and Grandio (nanohybrid) have better performances compared with GrandioSo (nanohybrid) and SDR (bulk fill), with Filtek Supreme having the worst infiltration.

Peutzfeldt et $\mathrm{al}^{47}$ instead show that the SDR material has the smallest marginal gap compared with Filtek Supreme (control) and Filtek bulk fill (bulk fill), which do not show statistically significant differences between them.

Juloski $^{38}$ et al point out that the SDR material presents the greatest microleakage.

Even in the studies that show a statistically significant difference between the materials tested, it should be emphasized that the best or worst marginal seal performance is not relative to the overall class of bulk composites, but is the prerogative of the individual products.

Technical skill, the need for isolation under the dam, and the time required to carry out the restoration are elements that cannot always be fully satisfied due to factors related to the skill of the operator, the anatomical site of the restoration, and errors that cannot be completely eliminated. To complete a restoration quickly, the industry has developed in the last 10 years resin-based composite materials with peculiar characteristics that allow them to be deposited in incremental layers up to $4 \mathrm{~mm}$ while reducing the time required and the possibility of making technical errors. These operational possibilities become particularly useful in conditions such as cavity preparations with root cement margin where we find a tissue that is not ideal for adhesive techniques, exposed to the high risk of infiltration during the isolation phase. The cavity margin of the cement preparation therefore represents a weak point in the interface of the adhesive restoration. ${ }^{49-54}$ In the presence of these anatomical assumptions, new technologies can be useful providing materials with high adaptability and marginal seal, with low polymerization shrinkage and therefore with reduced tension forces on the adhesive interface. Successfully Lo Giudice et $\mathrm{al}^{8}$ used a flowable composite at the interface with the root cementum to exploit the low elastic modulus of the material to reduce the effects of polymerization stress; however, it was impossible to obtain a marginal seal. Better standardization of the cavity would be useful; also in reference to the fact that bulk-fill composites seem to be more advantageous especially in deep cavities. ${ }^{16,55}$

A great variability is also present in the evaluation phase due to the presence of different techniques and consequently, of different methods for evaluating marginal integrity.

A further confounding factor is that materials with very heterogeneous characteristics are included in the class of bulk fill resin-based composite materials, which are further classified, in a variously incomplete way, based on viscosity.

However, with all the limitations described above, the selected studies show that there is substantially no statistically significant difference in the marginal integrity of the cement margins of cavity preparations restored with bulk fill composites compared with those restored with non-bulk composite.

Our results are in line with previous research: there is a significant heterogeneity within the class of bulk fill composites $^{55,56}$ not a better or worse seal is clearly observed. ${ }^{40,43,52,57-60}$

Furthermore, there is no need for the incremental technique that is highly sensitive, operator dependent, and prone to inevitable errors (contamination between the layers, incorporation of air bubbles between the layers) that can compromise the quality of the restoration. ${ }^{54,61,62}$

\section{Limitations}

Unfortunately, must be highlighted, an extreme heterogeneity of the studies: even though these are in vitro experiments, it is not possible to define the standard dimensions of the cavities of each study, since each investigator has chosen slightly different dimensions.

The extreme variability is found event in the choice of the material. Considering that it is difficult to classify bulk composites on the basis of their chemical characteristics, we carry out a classification on the basis of the macroscopic physical characteristics, which, however, is largely incomplete as they are also minimal variations in the content of filler or monomer $^{63}$ or molecules that accompany and modulate the photopolymerization is accompanied by variability of the physical behavior of the material, variability of the elastic modulus are significant even within the same category of materials in consideration of the fact that the filler content, which varies between the different bulk composites strongly influences the elastic modulus of the material. Certainly, a learning curve in the use of these materials is essential and furthermore it is necessary to consider the operator-addiction. The 
use of magnification systems, for example, as already evaluated in the literature, can be essential in the clinical results of this type of practice. ${ }^{33,64-66}$

The variability is also reflected in the absence or presence of artificial aging of the restoration and in the method of evaluating the marginal adaptation that, in fact, is performed in different ways in these studies: immersion in $0.5 \%$ basic fuchsin solution, immersion in 10\% methylene blue, immersion in $1 \%$ methylene blue, immersion in $2 \%$ Procion Red solution, and SEM analysis of the copies in epoxy resin.

Another fundamental aspect to underline is that the interproximal regions of bulk fill restorations have not always been coated with a traditional composite (as indicated by the manufacturer); this could have worsened the performance of the composites, as it was observed that the superficial microhardness of the two low viscosity bulk fill composites (SDR Dentsply; Venus Bulk Fill, Heraeus Kulzer) is significantly reduced by their exposure to solvents that simulate food solvents, hence the manufacturers' recommendations to cover the material with a cap of material composite. ${ }^{67}$ However, it has also been shown that the same SDR has, in a statistically significant manner, a lower polymerization stress than some traditional composites and some flowable composites ${ }^{35}$ and also compared with other low viscosity (base) bulk fill composites. ${ }^{68-70}$

\section{Conclusions}

The bulk fill technique is characterized by a shorter operating time and less dependence on the operator, and fewer procedural errors are detectable.

In conclusion, it can be stated that, with the limitations of the present study, from the data extracted from the review of the literature, there are no clear differences that indicate a better or worse marginal seal with bulk fill composites, while the time savings and operational simplification make it possible to make the direct restoration technique less dependent on the operator's expertise. Further studies like this could further clarify whether the use of these materials is more versatile than expected. Being able to use materials like this, which still demonstrate promising results, can make clinical practice easier and faster.

However, further studies are needed to gather further information, using a shared and standardized protocol that allows comparing the results of the different studies.

\section{Authors' Contributions}

P.F. conceptualized the manuscript; F.L. was in involved in methodology of the manuscript; B.G., S.A., P.M. were involved in software development; M.T.J.P., F.L. were involved in data curation and visualization; M.G. was involved in writing and preparation of original draft; L.F. was involved in writing, review, and editing of the manuscript; G.C. and L.R. were involved in supervision; L.F. was involved in project administration; all authors read and agreed to the published version of the manuscript.

\section{Conflict of Interest}

None declared.

\section{Acknowledgment}

A brief version of this manuscript has been presented in XXVII Congresso Nazionale CDUO, Italy. We would like to thank Cristina Tamà, Giuliano Calapaj, and Manuele Arcudi for those early version preparations.

\section{References}

1 Griffin SO, Griffin PM, Swann JL, Zlobin N. Estimating rates of new root caries in older adults. J Dent Res 2004;83(8):634-638

2 Michaelis W, Schiffner U, The Fourth German Oral Health Study (DMS IV). Köln: Institute of German Dentists, Deutscher Zahnärzte Verlag; 2006

3 Selvig KA. Biological changes at the tooth-saliva interface in periodontal disease. J Dent Res 1969;48(5):846-855

4 Takahashi N, Nyvad B. Ecological hypothesis of dentin and root caries. Caries Res 2016;50(4):422-431

5 Bergenholtz G, Cox CF, Loesche WJ, Syed SA. Bacterial leakage around dental restorations: its effect on the dental pulp. J Oral Pathol 1982;11(6):439-450

6 Pashley DH. Clinical considerations of microleakage. J Endod 1990;16(2):70-77

7 Hashimoto M, Ohno H, Sano H, Kaga M, Oguchi H. Degradation patterns of different adhesives and bonding procedures. J Biomed Mater Res B Appl Biomater 2003;66(1):324-330

8 Lo Giudice G, Cicciù M, Cervino G, Lizio A, Visco AM. Flowable resin and marginal gap on tooth third medial cavity involving enamel and radicular cementum: a SEM evaluation of two restoration techniques. Indian J Dent Res 2012;23(6):763-769

9 Prati C, Chersoni S, Cretti L, Mongiorgi R. Marginal morphology of Class V composite restorations. Am J Dent 1997;10(5):231-236

10 Lo Giudice R, Lizio A, Cervino G, et al. The horizontal root fractures. diagnosis, clinical management and three-year follow-up. Open Dent J 2018;12:687-695

11 Spencer P, Ye Q, Park J, et al. Adhesive/dentin interface: the weak link in the composite restoration. Ann Biomed Eng 2010;38(6):1989-2003

12 Yoshihara K, Yoshida Y, Hayakawa S, et al. Nanolayering of phosphoric acid ester monomer on enamel and dentin. Acta Biomater 2011;7(8):3187-3195

13 Nikaido T, Ichikawa C, Li N, et al. Effect of functional monomers in all-in-one adhesive systems on formation of enamel/dentin acid-base resistant zone. Dent Mater J 2011;30(5):576-582

14 Schroeder M, Correa IC, Bauer J, Loguercio AD, Reis A. Influence of adhesive strategy on clinical parameters in cervical restorations: a systematic review and meta-analysis. J Dent 2017;62:36-53

15 Hamama HH, Applications of Nanocomposite Materials in Dentistry. Elsevier Inc; Netherlands 2019

16 Van Ende A, De Munck J, Lise DP, Van Meerbeek B. Bulk-fill composites: a review of the current literature. J Adhes Dent 2017;19(2):95-109

17 Folwaczny M, Loher C, Mehl A, Kunzelmann KH, Hickel R. Class $\mathrm{V}$ lesions restored with four different tooth-colored materials-3-year results. Clin Oral Investig 2001;5(1):31-39

18 Namgung C, Rho YJ, Jin BH, Lim BS, Cho BH. A retrospective clinical study of cervical restorations: longevity and failure-prognostic variables. Oper Dent 2013;38(4):376-385

19 Dennison JB, Craig RG. Physical properties and finished surface texture of composite restorative resins. J Am Dent Assoc 1972;85(1):101-108 
20 Feilzer AJ, de Gee AJ, Davidson CL. Relaxation of polymerization contraction shear stress by hygroscopic expansion. J Dent Res 1990;69(1):36-39

21 Bausch JR, de Lange K, Davidson CL, Peters A, de Gee AJ. Clinical significance of polymerization shrinkage of composite resins. J Prosthet Dent 1982;48(1):59-67

22 Borkowski K, Kotousov A, Kahler B. Effect of material properties of composite restoration on the strength of the restoration-dentine interface due to polymerization shrinkage, thermal and occlusal loading. Med Eng Phys 2007;29(6):671-676

23 Kwon Y, Ferracane J, Lee IB. Effect of layering methods, composite type, and flowable liner on the polymerization shrinkage stress of light cured composites. Dent Mater 2012;28(7):801-809

24 Lee MR, Cho BH, Son HH, Um CM, Lee IB. Influence of cavity dimension and restoration methods on the cusp deflection of premolars in composite restoration. Dent Mater 2007;23(3):288-295

25 Park J, Chang J, Ferracane J, Lee IB. How should composite be layered to reduce shrinkage stress: incremental or bulk filling? Dent Mater 2008;24(11):1501-1505

26 Lo Giudice R, Puleio F, Verrusio C, Matarese M, Alibrandi A, Lizio A. Bulk vs wedge shape layering techniques in $\mathrm{V}$ class cavities: marginal infiltration evaluation. $\mathrm{G}$ Ital Endod 2017;31(2):73-77

27 Tomaszewska IM, Kearns JO, Ilie N, Fleming GJP. Bulk fill restoratives: to cap or not to cap-that is the question? J Dent 2015;43(3):309-316

28 Hamama HH, "Recent advances in posterior resin composite restorations." Applications of Nanocomposite Materials in Dentistry. Elsevier Inc; 2019

29 Goracci C, Cadenaro M, Fontanive L, et al. Polymerization efficiency and flexural strength of low-stress restorative composites. Dent Mater 2014;30(6):688-694

30 Hamano N, Ino S, Fukuyama T, Hickel R, Kunzelmann KH. Repair of silorane-based composites: microtensile bond strength of silorane-based composites repaired with methacrylate-based composites. Dent Mater J 2013;32(5):695-701

31 Baur V, Ilie N. Repair of dental resin-based composites. Clin Oral Investig 2013;17(2):601-608

32 Lassila LVJ, Nagas E, Vallittu PK, Garoushi S. Translucency of flowable bulk-filling composites of various thicknesses. Chin J Dent Res 2012;15(1):31-35

33 Bucuta S, Ilie N. Light transmittance and micro-mechanical properties of bulk fill vs. conventional resin based composites. Clin Oral Investig 2014;18(8):1991-2000

34 Moszner N, Fischer UK, Ganster B, Liska R, Rheinberger V. Benzoyl germanium derivatives as novel visible light photoinitiators for dental materials. Dent Mater 2008;24(7):901-907

35 Ilie $\mathrm{N}$, Hickel $\mathrm{R}$. Investigations on a methacrylate-based flowable composite based on the SDR ${ }^{\mathrm{TM}}$ technology. Dent Mater 2011;27(4):348-355

36 "Dentsply. SureFil SDR flow: posterior bulk fill flowable base [internet]. Milford: DENTSPLY; 2011 [Consultado 2014 mar 10]. Available at: http://www.surefilsdrflow. com/sites/default/files/SureFil_Technical_Manual.pdf. Accessed May 17, 2021

37 Mohammadi N, Kimyai S, Bahari M, Pournaghi-Azar F, Mozafari A. Effect of aluminum chloride hemostatic agent on microleakage of class $\mathrm{V}$ composite resin restorations bonded with all-in-one adhesive. Med Oral Patol Oral Cir Bucal 2012;17(5):e841-e844

38 Juloski J, Carrabba M, Aragoneses JM, Forner L, Vichi A, Ferrari M. Microleakage of Class II restorations and microtensile bond strength to dentin of low-shrinkage composites. Am J Dent 2013;26(5):271-277
39 Poggio C, Chiesa M, Scribante A, Mekler J, Colombo M. Microleakage in Class II composite restorations with margins below the CEJ: in vitro evaluation of different restorative techniques. Med Oral Patol Oral Cir Bucal 2013;18(5):e793-e798

40 Scotti N, Comba A, Gambino A, et al. Microleakage at enamel and dentin margins with a bulk fills flowable resin. Eur J Dent 2014;8(1):1-8

41 Webber MBF, Marin GC, Progiante PS, Lolli LF, Marson FC. Bulk-Fill resin-based composites: microleakage of class II restorations. J Surgical Clinical Dentistry 2014;2:15-19

42 Kalmowicz J, Phebus JG, Owens BM, Johnson WW, King GT. Microleakage of Class I and II composite resin restorations using a sonic-resin placement system. Oper Dent 2015;40(6):653-661

43 Al-Harbi F, Kaisarly D, Bader D. El Gezawi M. Marginal integrity of bulk versus incremental fill class II composite restorations. Oper Dent 2016;41(2):146-156

44 de Assis FS, Lima SN, Tonetto MR, et al. Evaluation of bond strength, marginal integrity, and fracture strength of bulk- vs incrementally-filled restorations. J Adhes Dent 2016;18(4):317-323

45 Behery H, El-Mowafy O, El-Badrawy W, Nabih S, Saleh B. Gingival microleakage of class II bulk-fill composite resin restorations. Dent Med Probl 2018;55(4):383-388

46 Haak R, Näke T, Park KJ, Ziebolz D, Krause F, Schneider H. Internal and marginal adaptation of high-viscosity bulk-fill composites in class II cavities placed with different adhesive strategies. [published correction appears in Odontology. 2019 Feb 4;] Odontology 2019;107(3):374-382

47 Peutzfeldt A, Mühlebach S, Lussi A, Flury S. Marginal gap formation in approximal "bulk fill" resin composite restorations after artificial ageing. Oper Dent 2018;43(2):180-189

48 García Marí L, Climent Gil A, LLena Puy C. In vitro evaluation of microleakage in class II composite restorations: high-viscosity bulk-fill vs conventional composites. Dent Mater J 2019;38(5):721-727

49 Kidd EA. Microleakage: a review. J Dent 1976;4(5):199-206

50 Hernandes NM, Catelan A, Soares GP, et al. Influence of flowable composite and restorative technique on microleakage of class II restorations. J Clin Investig Dent 2014;5(4):283-288

51 Majety KK, Pujar M. In vitro evaluation of microleakage of class II packable composite resin restorations using flowable composite and resin modified glass ionomers as intermediate layers. J Conserv Dent 2011;14(4):414-417

52 Campos EA, Ardu S, Lefever D, Jassé FF, Bortolotto T, Krejci I. Marginal adaptation of class II cavities restored with bulk-fill composites. J Dent 2014;42(5):575-581

53 Puleio F, Rizzo G, Nicita F, et al. Chemical and mechanical roughening treatments of a supra-nano composite resin surface: SEM and topographic analysis. Appl Sci (Basel) 2020;10:445710.3390/app10134457

54 Ruiz JL. Restorations with resin- based, bulk fill composites. Compend Contin Educ Dent 2010;31(5):14-17

55 Rizzante FAP, Mondelli RFL, Furuse AY, Borges AFS, Mendonça G, Ishikiriama SK. Shrinkage stress and elastic modulus assessment of bulk-fill composites. J Appl Oral Sci 2019;27:e20180132

56 Rizzante FAP, Duque JA, Duarte MAH, Mondelli RFL, Mendonça G, Ishikiriama SK. Polymerization shrinkage, microhardness and depth of cure of bulk fill resin composites. Dent Mater J 2019;38(3):403-410

57 Furness A, Tadros MY, Looney SW, Rueggeberg FA. Effect of bulk/incremental fill on internal gap formation of bulk-fill composites. J Dent 2014;42(4):439-449

58 Benetti AR, Havndrup-Pedersen C, Honoré D, Pedersen MK, Pallesen U. Bulk-fill resin composites: polymerization 
contraction, depth of cure, and gap formation. Oper Dent 2015;40(2):190-200

59 Heintze SD, Monreal D, Peschke A. Marginal quality of class II composite restorations placed in bulk compared to an incremental technique: evaluation with SEM and stereomicroscope. J Adhes Dent 2015;17(2):147-154

60 Roggendorf $\mathrm{MJ}$, Krämer $\mathrm{N}$, Appelt A, Naumann $\mathrm{M}$, Frankenberger R. Marginal quality of flowable 4-mm base vs. conventionally layered resin composite. J Dent 2011;39(10): 643-647

61 Pilo R, Oelgiesser D, Cardash HS. A survey of output intensity and potential for depth of cure among light-curing units in clinical use. J Dent 1999;27(3):235-241

62 Sakaguchi RL, Douglas WH, Peters MC. Curing light performance and polymerization of composite restorative materials. J Dent 1992;20(3):183-188

63 Asmussen E, Peutzfeldt A. Influence of UEDMA BisGMA and TEGDMA on selected mechanical properties of experimental resin composites. Dent Mater 1998;14(1):51-56
64 Leprince JG, Palin WM, Vanacker J, Sabbagh J, Devaux J, Leloup G. Physico-mechanical characteristics of commercially available bulk-fill composites. J Dent 2014;42(8):993-1000

65 Lo Giudice G, Lo Giudice R, Matarese G, et al. Evaluation of magnification systems in restorative dentistry. An in-vitro study. Dent Cadmos 2015;83(5):296-305

66 Lo Giudice G, Cicciù M, Cervino G, Lizio A, Visco AM. Flowable resin and marginal gap on tooth third medial cavity involving enamel and radicular cementum: a SEM evaluation of two restoration techniques. Indian J Dent Res 2012;23(6):763-769

67 Sunbul HA, Silikas N, Watts DC. Surface and bulk properties of dental resin-composites after solvent storage. Dent Mater 2016;32(8):987-997

68 Ishak H, Field J, German M. Baseline specimens of erosion and abrasion studies. Eur J Dent 2021;15(2):369-378

69 Cicciù M. Nanobiomaterials in dentistry: what's the consequent level. Eur J Dent 2018;12(2):161-162

70 MarovicD,TauböckTT,Attin T,Panduric V,TarleZ.Monomerconversion and shrinkage force kinetics of low-viscosity bulk-fill resin composites. Acta Odontol Scand 2015;73(6):474-480 